\title{
APPROXIMATION TO FIXED POINTS OF GENERALIZED NONEXPANSIVE MAPPINGS
}

\author{
CHI SONG WONG ${ }^{1}$
}

\begin{abstract}
Let $K$ be a convex subset of a uniformly convex Banach space. It is proved that if $K$ is compact, then the fixed points of a continuous generalized nonexpansive self-mapping $T$ on $K$ can be approximated by the iterates of $T_{t}$ with $t \in(0,1), T_{t}(x)=(1-t) x+t T(x), x \in K ; T_{t}$ is asymptotically regular if $T$ has a fixed point.
\end{abstract}

Let $(X, d)$ be a (nonempty) metric space. A function $\alpha$ of $X \times X$ into $[0, \infty)$ is symmetric if $\alpha(x, y)=\alpha(y, x)$ for all $x, y$ in $X$. Let $T$ be a self-mapping on $X$. $T$ is generalized nonexpansive if there exist symmetric functions $\alpha_{i}, i=1,2$, $\ldots, 5$, of $X \times X$ into $[0, \infty)$ such that

$$
\sup \left\{\sum_{i=1}^{5} \alpha_{i}(x, y): x, y \in X\right\} \leqslant 1
$$

and for all $x, y$ in $X$,

$$
\begin{aligned}
d(T(x), T(y)) \leqslant & a_{1} d(x, y)+a_{2} d(x, T(y))+a_{3} d(y, T(x)) \\
& +a_{4} d(x, T(x))+a_{5} d(y, T(y)),
\end{aligned}
$$

where $a_{i}=\alpha_{i}(x, y)$. It is clear that $T$ is generalized nonexpansive if it is nonexpansive $(d(T(x), T(y)) \leqslant d(x, y), x, y \in X$. R. Kannan first considered those $T$ which satisfy (2) with $a_{1}=a_{2}=a_{3}=0$ and $a_{4}=a_{5} \leqslant \frac{1}{2}$ [5]-[9]. S. Reich considered those $T$ which satisfy (2) with $a_{2}=a_{3}=0$ and with constants $a_{1}, a_{4}, a_{5}$ [11]-[13]. Recently, G. Hardy and T. Rogers considered those $T$ which satisfy (2) with constants $a_{i}$ 's [4]. In [3], K. Goebel, W. A. Kirk and Tawfik $\mathrm{N}$. Shimi proved that $T$ has a fixed point if $X$ is a weakly compact convex subset of a uniformly convex Banach space and if $T$ satisfies (2) with constant coefficients. Other related work can be found in [15]-[19]. In this paper, we shall investigate the theory of approximations to fixed points of generalized nonexpansive mappings.

1. Asymptotic regular mappings. Let $T$ be a self-mapping on a metric space

Received by the editors July 23, 1973 and, in revised form, November 1, 1974.

AMS (MOS) subject classifications (1970). Primary 47H10; Secondary 54H25.

1 This research was partially supported by the National Research Council of Canada Grant A8518. 
$(X, d) . T$ is asymptotically regular [1] if for any $x$ in $X,\left\{d\left(T^{n+1}(x), T^{n}(x)\right)\right\}$ converges to 0 . For a Banach space $B$, we shall use $d$ to denote the metric for $B$ induced by the norm \|\| of $B$.

THEOREM 1. Let $X$ be a convex subset of a uniformly convex Banach space $B$. Let $T$ be a generalized nonexpansive self-mapping on $X$. Suppose that the fixed point set $F=\{x \in X: T(x)=x\}$ is nonempty. Then for each $t$ in $(0,1)$, the mapping $T_{t}$ defined by

$$
T_{t}(x)=(1-t) x+t T(x), \quad x \in X,
$$

is asymptotically regular.

Proof. Let $x_{0} \in X, x_{n+1}=T_{t}\left(x_{n}\right), n=0,1,2, \ldots$ Since

$$
T_{t}(x)-x=t(x-T(x)), \quad x \in X,
$$

it suffices to prove that $\left\{d\left(x_{n}, T\left(x_{n}\right)\right)\right\}$ converges to 0 . Since $T$ is a generalized nonexpansive mapping, there exist symmetric functions $\alpha_{i}, i=1,2, \ldots, 5$, of $X \times X$ into $[0, \infty)$ such that $\sum_{i=1}^{\infty} \alpha_{i} \leqslant 1$ and for all $x, y$ in $X$,

$$
\begin{aligned}
d(T(x), T(y)) \leqslant & a_{1} d(x, y)+a_{2} d(x, T(y))+a_{3} d(y, T(x)) \\
& +a_{4} d(x, T(x))+a_{5} d(y, T(y)),
\end{aligned}
$$

where $a_{i}=\alpha_{i}(x, y)$. Each $\alpha_{i}$ is symmetric. So we may, by calculating $(d(T(x), T(y))+d(T(y), T(x))) / 2$, assume that $\alpha_{2}=\alpha_{3}, \alpha_{4}=\alpha_{5}$. Thus $\alpha_{3}$ $+\alpha_{4} \leqslant \frac{1}{2}$. Now let $x \in X, y \in F$. From (5) (with $a_{i}=\alpha_{i}(x, y)$ ),

$$
\begin{aligned}
d(T(x), y) & =d(T(x), T(y)) \\
& \leqslant\left(a_{1}+a_{2}\right) d(x, y)+a_{3} d(y, T(x))+a_{4} d(x, T(x)) .
\end{aligned}
$$

Since $d(x, T(x)) \leqslant d(x, y)+d(y, T(x))$,

$$
\left(1-a_{3}-a_{4}\right) d(T(x), y) \leqslant\left(a_{1}+a_{2}+a_{4}\right) d(x, y) .
$$

Since $1-a_{3}-a_{4}>0$ and $1-a_{3}-a_{4} \geqslant a_{1}+a_{2}+a_{4}$,

$$
d(T(x), y) \leqslant d(x, y) .
$$

Also

$$
\begin{aligned}
\left\|y-T_{t}(x)\right\| & =\|y-(1-t) x-t T(x)\| \\
& =\|(1-t)(y-x)+t(y-T(x))\| \\
& \leqslant(1-t)\|y-x\|+t\|y-T(x)\| .
\end{aligned}
$$

By (6) and (8),

$$
\left\|y-T_{t}(x)\right\| \leqslant\|y-x\| .
$$

so $\left\{\left\|y-x_{n}\right\|\right\}$ is bounded by $M=\left\|y-x_{0}\right\|$. If $y=x_{n}$ for some $n$, then from (9), $\left\{x_{n}\right\}$ converges to $y$ and the proof is complete. So we may assume that 
$y \neq x_{n}$ for all $n=0,1,2, \ldots$ We shall now assume that $t \leqslant \frac{1}{2}$. Note first that

$$
\begin{aligned}
\left\|y-x_{n+1}\right\| & =\left\|t\left(y-x_{n}+y-T\left(x_{n}\right)\right)+(1-2 t)\left(y-x_{n}\right)\right\| \\
& \leqslant t\left\|y-x_{n}+y-T\left(x_{n}\right)\right\|+(1-2 t)\left\|y-x_{n}\right\| \\
& \leqslant 2 t\left\|y-x_{n}\right\|\|(u+v) / 2\|+(1-2 t)\left\|y-x_{n}\right\|,
\end{aligned}
$$

where

$$
u=\frac{y-x_{n}}{\left\|y-x_{n}\right\|}, \quad v=\frac{y-T\left(x_{n}\right)}{\left\|y-x_{n}\right\|}
$$

Since $B$ is uniformly convex,

$$
\delta(\epsilon)=\inf \{1-\|x+y\| / 2:\|x\| \leqslant 1,\|y\| \leqslant 1,\|x-y\| \geqslant \epsilon\}
$$

is positive for $\epsilon$ in $(0,2]$. Also $\delta(0)=0$. From (11),

$$
\|(u+v) / 2\| \leqslant 1-\delta\left(\left\|x_{n}-T\left(x_{n}\right)\right\| /\left\|y-x_{n}\right\|\right) .
$$

Since $\delta$ is monotonically nondecreasing on $[0,2]$,

$$
\|(u+v) / 2\| \leqslant 1-\delta\left(\left\|x_{n}-T\left(x_{n}\right)\right\| / M\right) .
$$

From (10) and (12),

$$
\left\|y-x_{n+1}\right\| \leqslant\left(1-2 t \delta\left(\left\|x_{n}-T\left(x_{n}\right)\right\| / M\right)\right)\left\|y-x_{n}\right\| .
$$

By (13) and induction,

$$
\left\|y-x_{n+1}\right\| \leqslant \prod_{j=0}^{n}\left(1-2 t \delta\left(\left\|x_{j}-T\left(x_{j}\right)\right\| / M\right)\right) M .
$$

Suppose to the contrary that $\left\{\left\|x_{n}-T\left(x_{n}\right)\right\|\right\}$ does not converge to 0 . Then there exists a subsequence $\left\{x_{k(n)}\right\}$ of $\left\{x_{n}\right\}$ such that $\left\{\left\|x_{k(n)}-T\left(x_{k(n)}\right)\right\|\right\}$ converges to some $r \in(0, \infty)$. Since $\delta$ is monotonically nondecreasing and $1-2 t \delta\left(\left\|x_{j}-T\left(x_{j}\right)\right\| / M\right) \in[0,1]$ for each $j$, we have from (14) that for large $n$ 's,

$$
\left\|y-x_{k(n+1)}\right\| \leqslant(1-2 t \delta(r / 2 M))^{n} M .
$$

So $\left\{x_{k(n)}\right\}$ converges to $y$. By (6), $\left\{T\left(x_{k(n)}\right)\right\}$ also converges to $y$. Thus $\left\{\left\|x_{k(n)}-T\left(x_{k(n)}\right)\right\|\right\}$ converges to 0 , a contradiction to the choice of $r$. If $t>\frac{1}{2}$, then $1-t \leqslant \frac{1}{2}$ and we can repeat the same argument by writing (10) as

$$
\begin{aligned}
\left\|y-x_{n+1}\right\| & =\left\|(1-T)\left(y-x_{n}+y-T\left(x_{n}\right)\right)+(2 t-1)\left(y-T\left(x_{n}\right)\right)\right\| \\
& \leqslant(1-t)\left\|y-x_{n}+y-T\left(x_{n}\right)\right\|+(2 t-1)\left\|y-T\left(x_{n}\right)\right\| \\
& \leqslant(1-t)\left\|y-x_{n}\right\|\|(u+v) / 2\|+(2 t-1)\left\|y-x_{n}\right\| ;
\end{aligned}
$$

a contradiction will then be obtained as before if we interchange the roles of 
$t$ and $1-t$. Hence $T_{t}$ is asymptotically regular.

The above result was proved in [14] for nonexpansive mappings.

\section{Successive approximations.}

THEOREM 2. Let $X$ be a compact convex subset of a strictly convex Banach space $B$. Let $T$ be a generalized nonexpansive self-mapping on $X$. Then:

(a) The fixed point set $F=\{x \in X: T(x)=x\}$ of $T$ is convex.

(b) If $T$ is continuous, then $F$ is nonempty and compact.

(c) If $T$ is continuous, then for any $x_{0}$ in $X, t$ in $(0,1),\left\{T_{t}^{n}\left(x_{0}\right)\right\}$ converges to a fixed point of $T$, where $T_{t}(x)=(1-t) x+t T(x), x \in X$.

Proof. (a) Let $x, y \in F, t \in(0,1)$, and, and $z=(1-t) x+t y$. Then by (6), $d(T(z), x) \leqslant d(z, x)=t d(x, y)$. Similarly, $d(T(z), y) \leqslant(1-t) d(x, y)$. By the strict convexity of $B, T(z)=z$. Hence $F$ is convex.

(b) By continuity and the Schauder-Tychonoff theorem, $F$ is compact and nonempty.

(c) Let $n \geqslant 0, x_{n}=T_{t}^{n}\left(x_{0}\right)$. Since $X$ is compact, $\left\{x_{n}\right\}$ has a subsequence $\left\{x_{k(n)}\right\}$ which converges to some point $x$ in $X$. We shall prove that $x$ is a fixed point of $T$. From $(9),\left\{d\left(x_{n}, y\right)\right\}$ is monotonically nonincreasing. So by continuity of \|\| and $T_{t}$,

$$
\begin{aligned}
\|x-y\| & =\lim _{n \rightarrow \infty}\left\|x_{k(n+1)}-y\right\| \leqslant \lim _{n \rightarrow \infty}\left\|x_{k(n)+1}-y\right\| \\
& =\lim _{n \rightarrow \infty}\left\|T_{t}\left(x_{k(n)}\right)-y\right\|=\left\|T_{t}(x)-y\right\| .
\end{aligned}
$$

By (9) and (15),

$$
\left\|T_{t}(x)-y\right\|=\|x-y\|
$$

Note that

$$
\begin{aligned}
\left\|T_{t}(x)-y\right\| & =\|(1-t) x+t T(x)-y\| \\
& =\|(1-t)(x-y)+t(T(x)-y)\| \\
& \leqslant(1-t)\|x-y\|+t\|T(x)-y\| \\
& \leqslant(1-t)\|x-y\|+t\|x-y\|=\|x-y\| .
\end{aligned}
$$

Combining (16) and (17), we conclude that all inequalities in (17) are equalities. So

$$
\|(1-t)(x-y)+t(T(x)-y)\|=(1-t)\|x-y\|+t\|T(x)-y\|
$$

and

$$
\|x-y\|=\|T(x)-y\| .
$$

By (19) and the strict convexity of $B$, either $x=y$ or $T(x)-y=s(x-y)$ for some $s>0$. From (19), $s=1$. So $x$ is a fixed point of $T$. By $(18),\left\{d\left(x_{n}, x\right)\right\}$ is monotonically nondecreasing. Hence $\left\{x_{n}\right\}$ converges to $x$. 
The above result was proved in [2] for nonexpansive mappings.

REMARKS. We thank the referees for pointing out that it can be proved that our results more or less follow from Lemmas 2.1 and 2.2 and Corollary 2.3 of the recent paper [10] by W. V. Petryshyn and T. E. Williamson, Jr. The original manuscript of our work was prepared at the University of Alberta in the summer of 1972 and was referred to in [19].

\section{REFERENCES}

1. F. E. Browder and W. V. Petryshyn, The solution by iteration of nonlinear functional equations in Banach spaces, Bull. Amer. Math. Soc. 72 (1966), 566-570. MR 32 \#155a.

2. M. Edelstein, A remark on a theorem of M. A. Krasnoselski, Amer. Math. Monthly 73 (1966), 509-510. MR 33 \#3072.

3. K. Goebel, W. A. Kirk and Tawfik N. Shimi, A fixed point theorem in uniformly convex spaces, Bol. Un. Mat. Ital., 47 (1973), 65-75. MR 47 \#9367.

4. G. F. Hardy and T. D. Rogers, $A$ generalization of a fixed point theorem of Reich, Canad. Math. Bull. 16 (1973), 201-206. MR 48 \#2847.

5. R. Kannan, Some results on fixed points, Bull. Calcutta Math. Soc. 60 (1968), 71-76. MR 41 \#2486.

6. - Some results on fixed points. II, Amer. Math. Monthly 76 (1969), 405-408. MR 41 \#2487.

7. - Some results on fixed points. III, Fund. Math. 70 (1971), 169-177. MR 44 \# 879.

8. - Some results on fixed points. IV, Fund. Math. 74 (1972), 181-187. MR 45 \#9310.

9. - Fixed point theorems in reflexive Banach spaces, Proc. Amer. Math. Soc. 38 (1973), 111-118. MR 47 \#2448.

10. W. V. Petryshyn and T. E. Williamson, Jr., Strong and weak convergence of the sequence of successive approximations for quasi-nonexpansive mappings, J. Math. Anal. Appl. 43 (1973), 459497. MR 48 \#4854.

11. Simeon Reich, Some remarks concerning contraction mappings, Canad. Math. Bull. 14 (1971), 121-124. MR 45 \# 1145.

12. - Kannan's fixed point theorem, Bol. Un. Mat. Ital. (4) 4 (1971), 1-11. MR 46 \#4293.

13. - Fixed points of contractive functions, Bol. Un. Mat. Ital. (4) 4 (1972), 26-42. MR 46 \# 8206.

14. H. Schaefer, Uber die Methode sukzessiver Approximationen, Jber. Deutsch Math. Verein. 59 (1957), 131-140. MR 18, 811.

15. Paolo Soardi, Su un problema di punto unito di S. Reich, Bol. Un. Mat. Ital. (4) 4 (1971), 841-845. MR 46\#741.

16. Chi Song Wong, Fixed point theorems for generalized nonexpansive mappings, J. Australian Math. Soc. 18 (1974), 265-276.

17. - Common fixed points for two mappings, Pacific J. Math. 48 (1973), 299-312.

18. - A fixed point theorem for a class of mappings, Math. Ann. 204 (1973), 97-103.

19. - Fixed points of certain self maps on an interval, Proc. Amer. Math. Soc. 42 (1974), $234-235$.

Department of Mathematics, University of Windsor, Windsor, Ontario, Canada 